\title{
LETTER TO THE EDITOR: META-ANALYTIC VALIDATION OF NEW ‘AUS' FEBRILE NEUTROPENIA RISK SCORE
}

\author{
Robert Phillips ${ }^{1}$ and Jessica Morgan ${ }^{1}$ \\ ${ }^{1}$ University of York
}

June 25, 2020

The challenge of multiple paediatric febrile neutropenia clinical decision rules has been well described, and the difficulties with ever-expanding variants based on individual datasets discussed extensively. ${ }^{1}$ The recalibration of the SPOG rule undertaken by Haeusler and colleagues ${ }^{2}$ (creating the 'AUS' rule) for a practical, bedside tool which would be able to risk stratify episodes of FN. This letter reports a further validation in a meta-analytic dataset from the 'Predicting Infectious Complications in Children with Cancer' (PICNICC) collaboration.

Briefly, the PICNICC collaboration was formed to develop a robust prediction rule for febrile neutropenia, with methods and materials detailed in previous publications. ${ }^{1,3}$ Over 8000 episodes of 33 different candidate predictor variables and seven clinically relevant outcomes have been collated from 26 study groups, with varied completeness. The 'AUS' rule uses three equally weighted factors to scale the risk of complications in an episode of FN, summed between 0 and 3.These factors are: preceding chemotherapy more intensive than acute lymphoblastic leukaemia maintenance, platelet count less than $50 \mathrm{~g} / \mathrm{L}$, total white cell count lower than 300 cells $/ \mathrm{mm}^{3}$. The clinical response can be scaled according to this score, with values of 0 and 1 considered as 'lower risk'.

We evaluated the association between the AUS rule and bacterial infection using these data, reporting the discrimination (Area Under the receiver-operator Curve, AUC) and proportion of episodes classed as lower risk (scoring 0 or 1 ). Analyses were undertaken using $\mathrm{R}$ (v3.2.0).

1520 episodes contributed to the analysis, with 301 episodes of documented bacterial infection. The discriminatory ability appeared very similar to Haeusler's values; AUC 0.64 (95\% CI 0.61 to 0.68) compared with the original AUC 0.67 (95\% CI 0.63 to 0.71). Using the AUS rule on the PICNICC dataset would have identified $44 \%(668 / 1520)$ of the population as a lower risk group (score 1 or 0$)$.

This reassuring data has led to the introduction of an AUS rule based system to shorten the duration of antibiotic therapy, in concordance with UK National and International guidelines[3,4]. This now-validated rule will reduce hospitalisation for febrile neutropenic episodes in the UK, which was of particular importance during the 2020 SARS-CoV-2 coronavirus pandemic.

\section{References}

[1] Phillips B, Morgan JE, Haeusler GM On behalf of the PICNICC Collaborative. Individual participant data validation of the PICNICC prediction model for febrile neutropenia. Archives of Disease in Childhood 2020;105:439-445 DOI:10.1136/archdischild-2019-317308

[2] Haeusler GM, Phillips R, Slavin MA, Babl FE, De Abreu Lourenco R, Mechinaud F, et al. Re-evaluating and recalibrating predictors of bacterial infection in children with cancer and febrile neutropenia. EClinicalMedicine. DOI: 10.1016/j.eclinm.2020.100394 
[3] Phillips, R., Sung, L., Amman, R. et al. Predicting microbiologically defined infection in febrile neutropenic episodes in children: global individual participant data multivariable meta-analysis. Br J Cancer 2016:114;623-630 DOI: 10.1038/bjc.2016.28

[4] Phillips R, Hancock B, Graham J, Bromham N, Jin H, Berendse S. Prevention and management of neutropenic sepsis in patients with cancer: summary of NICE guidance. BMJ. 2012;345:e5368.

[5] Lehrnbecher T, Robinson P, Fisher B, Alexander S, Ammann RA, Beauchemin M, et al. Guideline for the Management of Fever and Neutropenia in Children With Cancer and Hematopoietic Stem-Cell Transplantation Recipients: 2017 Update. J Clin Oncol. 2017;35(18):2082-94. 